\title{
AS FACES DO JOGO/BRINCADEIRA NA EDUCAÇÃO INFANTIL: UMA LEITURA DE WALTER BENJAMIN
}

Anita Helena Schlesener

\begin{abstract}
RESUMO
Este artigo apresenta algumas reflexões sobre educação infantil a partir de escritos de Walter Benjamin a fim de explicitar os conceitos de jogo e brincadeira na aprendizagem infantil. Benjamin sugere uma pedagogia que não adapte a criança às exigências do mundo adulto, mas que lhe garanta as condições para a construção de sua identidade e suas características lúdicas e sensoriais. O significado da mímesis, enquanto uma relação fraterna com as coisas e ao mesmo tempo de confronto com o mundo adulto, é abordado a partir de textos extraídos da extensa obra do autor. A questão política que perpassa a educação se encontra na tarefa de superar um conhecimento meramente informativo e utilitário, para articular lúdico e racional na educação infantil.
\end{abstract}

Palavras-chave: Educação. Jogo. Brincadeira. Mímesis. Walter Benjamin.

\section{THE FACES OF THE GAME/PLAY IN EARLY CHILDHOOD EDUCATION: A READING OF WALTER BENJAMIN}

\begin{abstract}
This paper approach some reflections on childhood education as of the writings of Walter Benjamin in order to clarify the concepts of game and play in children's learning. Benjamin suggests a pedagogy that does not fit the child to the demands of the adult world, but that garantees the conditions for the construction of their identity and ensures its ludic and sensorial characteristics. The meaning of mimesis as a fraternal relationship with things and at the same time confront the adult world, is approached from texts extracted from the extensive work of the author. The political question that pervades education is the task of overcoming a merely informative and utility knowledge, to articulate ludic and rational childhood education.
\end{abstract}

Keywords: Education. Game. Play. Mimesis. Walter Benjamin.

Doutora em História pela UFPR, com estágio em Milão (IT). Pós-doutorado em Educação na UNICAMP. Professora de Filosofia Política e Estética na UFPR de 1976 a 2004. Professora do Programa de Mestrado e Doutorado em Educação da Universidade Tuiuti do Paraná. Brasileira, residente em Curitiba - PR. Email: anita.helena@libero.it 


\section{Introdução}

A criança olha na direção da distante Libéria através de um binóculo de ópera segurado ao contrário: lá está ela, atrás de seu trechinho de mar, com suas palmeiras, exatamente como a mostram os selos. (BENJAMIN, 1987, 59)

O objetivo desse trabalho é desenvolver algumas reflexões sobre o significado do jogo ou brincadeira nos processos de cognição infantil tendo como referência principal alguns escritos de Walter Benjamin. Uma das questões mais instigantes nos escritos deste pensador é o modo como, nos mais variados temas que aborda, desponta aqui e ali, explícita ou implicitamente, a questão da educação. A forma como a criança realiza seu conhecimento do mundo por meio dos jogos e brincadeiras também a insere no mundo social na medida em que ela assimila (e reinventa) as coisas. Ao explicitar as características do jogo na formação da criança pretendemos ainda acentuar aspectos que assemelham e/ou diferenciam o jogo infantil do jogo adulto na invenção/ reprodução do mundo social no qual se está inserido. Nascida em um contexto social que a condiciona, inserida na historia e na cultura, a criança inicia um processo de aprendizagem e de criação que tanto pode desenvolver suas capacidades cognitivas e sensoriais quanto pode adaptá-la ao contexto. Benjamin sugere uma pedagogia que não adapte a criança às exigências do mundo adulto, mas que Ihe garanta as condições para a construção de sua identidade e preserve suas características lúdicas e sensoriais.

Pretende-se ainda levantar algumas questões sobre a importância do jogo na educação infantil enquanto uma dinâmica de conhecimento e de socialização da criança. Para tanto, tentaremos explicitar o duplo caráter da repetição nos processos educativos da criança (e do adulto), na relação/distinção entre jogar e brincar expressos nas formas de adaptação/criatividade (reprodução de normas/fantasia e invenção), alienação/emancipação (aceitação passiva da reaidade/conhecimento de si e do mundo).

O conceito jogo é ambíguo, extensivo a diversas formas de ação, de modo que uma abordagem sobre seus significados se enriquece na medida em que explicite essa ambiguidade tanto no âmbito teórico quanto na atividade empírica, visto que a ação e o conhecimento se articulam e se implicam mutuamente. Jogar 
implica sempre interagir com o outro (ou com a máquina, se pensarmos nos jogos eletrônicos) numa relação de confronto ou de troca e, em algumas situações, de cumplicidade.

Do ponto de vista histórico, o termo jogar e a prática do jogo na vida do homem foram abordados por autores das mais diversas tendências teóricas nas áreas da sociologia, da filosofia, da educação física, da cultura, da psicologia, da pedagogia, entre outras. Da perspectiva filosófica, o conceito pode ser rastreado desde os escritos de Platão, mas sua importância pedagógica se acentua a partir do século XVIII, redefinindo-se na medida em que se constrói a imagem moderna de infância, no contexto da consolidação das relações de poder que caracterizam a sociedade burguesa.

Entre os autores que refletiram sobre o tema (aqueles que Benjamin abordou direta ou indiretamente, bem como aqueles que posteriormente dialogaram com o autor), podemos citar Friedrich Schiller (1795) nas Cartas XII, XIII e XIV, que compõe A Educação Estética do Homem. Com base nos pressupostos gnosiológicos kantianos, Schiller argumenta que agimos movidos por duas forças ou impulsos opostos: o sensível, parte da natureza física do homem, e o formal, parte de nossa natureza racional. Dessas duas dimensões antagônicas, a primeira é passiva, enquanto a segunda é ativa e controladora e de sua interação nasce a cultura. As tensões resultantes do antagonismo precisam ser resolvidas e a harmonia ou a articulação entre esses dois opostos ocorre no âmbito da estética por meio do "impulso lúdico", que reconcilia matéria e forma, natureza e espirito, necessidade e liberdade, particular e universal. O lúdico encontra sua expressão no jogo, que desenvolve e atualiza as capacidades estéticas do homem. ${ }^{1}$ A importância da leitura de Schiller se apresenta no fato que ele reconhece implicitamente no impulso lúdico, enquanto mediador das tensões, não apenas a dimensão estética do problema, mas também a sua dimensão política. $^{2}$

\footnotetext{
1 SCHILLER, F. A Educação Estética do Homem. São Paulo: lluminuras, 1989, p. 67-79. Uma análise interessante dos conceitos de Schiller é efetuada por MARCUSE, H. Eros e civilização. Uma interpretação filosófica do pensamento de Freud. Rio de Janeiro: Zahar, 1972, p. 166-170. Marcuse acentua o caráter mediador do impulso lúdico, bem como a função da arte em mediar os princípios de prazer e de realidade.

2 A dimensão política da filosofia de Schiller é um tema importante, mas não cabe aqui aprofundá-lo.
} 
Na distinção entre o jogar e o brincar, nas práticas do adulto o jogo assume, em geral, a característica do jogo de azar. Balzac, no conto Un ménage de garçon, escrito em 1841, falava do jogo na sua forma mecânica e repetitiva como "uma paixão universalmente condenada e nunca estudada, nunca vista como o ópio da miséria. Quem imaginaria que a loteria, a fada mais poderosa do mundo, iria desenvolver esperanças mágicas?" Prazeres e sonhos que duram um instante. $\mathrm{O}$ sonho de felicidade (e de ascensão social) que encanta as massas e as faz cair num sono letárgico. A loteria é o ópio da miséria. ${ }^{3}$ Walter Benjamin não cita Balzac, mas acentua que o jogo, como qualquer outra paixão, envolve e mobiliza todos os órgãos dos sentidos, "sem excluir o sentido atávico da clarividência", o olhar. (BENJAMIN, 1987, 264-5)

No escrito Passagens, Benjamin nos contempla com uma serie de observações sobre o jogo de azar e sua compulsividade, forma como o adulto ocupa seu tempo de lazer (com evocações da infância) e uma das mais interessantes foi retirada de um texto de Paul Lafargue publicado em 1906, com observações bastante instigantes, que poderiam ser aplicadas hoje ao mundo das finanças; mostrando como o funcionamento da bolsa de valores se assemelha ao jogo de azar, o autor acentua:

\begin{abstract}
O desenvolvimento econômico moderno como um todo tende a transformar, cada vez mais, a sociedade capitalista em um enorme cassino internacional, onde os burgueses ganham e perdem capitais em consequência de acontecimentos que Ihes permanecem desconhecidos... O 'inescrutável' reina na sociedade burguesa como num antro de jogo... (...) O capitalista, cuja fortuna está aplicada em valores imobiliários, submetidos a oscilações de preço e dividendos cujas causas desconhece, é um jogador profissional... (BENJAMIN, 2009, 538)
\end{abstract}

As citações se estendem ao longo do Arquivo $\mathrm{O}$ e uma delas recorda $\mathrm{O}$ argumento de Anatole France sobre o jogo de azar, em Le Jardin d'Épicure: "o que é o jogo senão a arte de viver num segundo as mudanças que o destino só produz ao

3 Para Gramsci, as palavras de Balzac podem ter sugerido a expressão "ópio do povo", utilizada por Marx na Crítica da Filosofia do Direito de Hegel, publicada em 1844. Gramsci comenta ainda que a sugestão de Balzac pode ter sido mesclada com a de Pascal (cujos Pensamentos foram publicados em 1670 e reimpressos em 1843), "que compara a religião com o jogo de azar, com as apostas". (GRAMSCI, Quaderni del Carcere. 1978, p. 346-7. A referência a Balzac foi retirada desse texto de Gramsci, com livre tradução nossa).

Doutora em História pela UFPR, com estágio em Milão (IT). Pós-doutorado em Educação na UNICAMP. Professora de Filosofia Política e Estética na UFPR de 1976 a 2004. Professora do Programa de Mestrado e Doutorado em Educação da Universidade Tuiuti do Paraná. Brasileira, residente em Curitiba - PR. Email: anita.helena@libero.it 
longo de muitas horas e mesmo de muitos anos". O jogo também produz satisfação na medida em que a "atração do perigo subjaz a todas as grandes paixões. Não há volúpia sem vertigem. O prazer misturado com o medo embriaga", ou seja, o que encanta no jogo de azar e se transforma em compulsão é a mistura de prazer e terror que ele implica (BENJAMIN, 2009, 539) Essa mistura de prazer e de terror também envolve a brincadeira infantil, como Benjamin recorda em alguns momentos.

Charles Baudelaire (1861) também nos presenteou com belas reflexões sobre o jogo, tanto na forma repetitiva e mecânica da loteria ou do azar, quanto no modo criativo de brincar como aprendizagem do mundo na vida das crianças. A sensibilidade do poeta que, nas recordações de infância, salienta o sentimento contraditório vivido no horror e, ao mesmo tempo, no êxtase da vida. A criança, como o convalescente, goza da "faculdade de se interessar vivamente pelas coisas, mesmo pelas mais triviais em aparência". A criança, como o poeta, absorve com alegria a forma e a cor. "O gênio nada mais é do que a infância reencontrada". (...) é "a essa curiosidade profunda e alegre que é necessário atribuir o olho fixo e animalescamente extático das crianças diante do novo, qualquer que seja ele". ${ }^{4}$

Outros autores importantes na leitura de Benjamin foram: Karl Gross (1899), que publicou o livro Spiele der Menschen (Jogos Humanos), no qual apresenta uma teoria da brincadeira a partir da análise dos gestos lúdicos, para classificar os jogos em três grandes grupos: os sensoriais, os motores e os que desenvolvem funções mentais como: a imaginação, a memoria, a atenção e o raciocínio; os que atuam nas sensações afetivas ou na vontade. Essa análise foi retomada e enumerada mais tarde por Willy Haas (1928) que, conforme Benjamin, classifica os jogos em: "brincadeiras de perseguição" (gato e rato), "animal-mãe" que protege os filhotes e, em terceiro lugar, a "luta pela presa" ou a competição. Para Benjamin, seria de se investigar com mais profundidade os jogos relacionados aos impulsos sexuais, assim como "a grande lei que, além de todas as regras e ritmos individuais, rege o mundo da brincadeira em sua totalidade: a lei da repetição".(BENJAMIN, 1985, 252)

4 BAUDELAIRE, C. O pintor da vida moderna. In: Obras estéticas. Filosofia da imaginação criadora. Petrópolis: Vozes, 1993, p. 223-4 - grifo do autor. 
A teoria de Gross foi retomada e reelaborada também por Claparede, que distinguiu dois grandes grupos de jogos: um que se refere às funções mentais em geral (percepção, motricidade, racionalização, sentimento) e um segundo grupo que abrange funções especiais (imitação, luta, sociabilidade, etc.). Essas classificações foram importantes nas abordagens psicológicas e pedagógicas desenvolvidas no curso do século XX.

Salienta-se ainda Karl Groebel (1928), que consagrou um livro primoroso à história dos brinquedos, livro que mereceu dois belos estudos de Benjamin. Um dos méritos dessa obra, conforme Benjamin, foi mostrar os vínculos do brinquedo com a cultura popular em sua configuração coletiva, assim como os condicionamentos econômicos e da cultura técnica das coletividades sobre a produção do brinquedo. A obra evidencia a passagem de um trabalho artesanal voltado para o lazer da comunidade para a produção industrial e especializada (concomitante com a elaboração de uma ideia genérica de infância). Para Benjamin, nesse trabalho monumental Groebel renova tanto o conhecimento do brinquedo quanto a teoria da brincadeira apresentada por Gross e por Haas. (BENJAMIN, 1985, 244-253)

Não se pode deixar de lembrar Jean Piaget, na sua teoria da cognição infantil, na qual o jogo é uma forma de expressão espontânea que tem caráter educativo e de formação das estruturas do pensamento, pelo modo como eleva o nível de compreensão da realidade e prepara a criança para a adaptação a normas objetivas que a inserem no mundo social. Um trabalho significativo no campo da pedagogia, enquanto privilegia a racionalidade abstrata e formal e tenta descobrir os caminhos educativos de superação da forma cognitiva primitiva da fase pré-verbal e sensóriomotora da criança.

As pesquisas mais específicas sobre o termo jogo aparecem no início do século XX e, delas, ressaltamos a leitura de Johan Huizinga (1938), que desenvolve uma reflexão sobre o Homo Ludens, acentuando os aspectos do jogo na sua dimensão cultural e de formação humana que, historicamente, se realiza nas festas, nas competições, no teatro e na dança. Como expressão da vida cultural, o jogo pode assumir as mais variadas características, como fenômeno cultural, competição, 
expressão artística ou figuração mítica, ou seja, toda atividade lúdica desenvolvida ou para preencher o tempo livre, ou para consolidar processos de socialização.

Para o adulto, já adaptado ao contexto social, o jogo pode apresentar-se como evasão do cansaço do cotidiano do trabalho, ou seja, evasão de uma realidade na qual o trabalho não se apresenta como a expressão de uma atividade livre e criativa, questão já levantada por Schiller; nesse contexto, o jogo alivia tensões e pode ser uma recreação ou um divertimento visto que, na sociedade capitalista a redução da força de trabalho a mera mercadoria e do tempo de lazer a tempo de reposição das forças de trabalho transforma o jogo num reforço das condições sociais alienantes. ${ }^{5}$

Mais recentemente Gunter Gebauer e Christoph Wulf aprofundam as análises do jogo a partir do significado da formação por imitação nos processos educativos no âmbito da história e da cultura pela explicitação do conceito de mímesis. Para esses autores, muito mais que simples imitação, a mímesis se presenta como a ação humana capaz de conhecer produzindo semelhanças, ou seja, capaz de “'fazer-se parecido', 'trazer algo à representação', encenar e expressar-se pela arte, principalmente a dança, embora o termo não se restrinja a essa atividade", mas se estenda a "quase todas as áreas humanas da ação, da imaginação, do falar e do pensar", enquanto "condição imprescindível à vida social. (GEBAUER e WULF, 2004, 21) Para explicitar sua definição os autores reconstroem a história do conceito desde Platão a Derrida, mostrando como a mimesis se traduz em apropriação de formas de comportamento e de assimilação cultural com a transmissão de conhecimentos para o desenvolvimento individual e coletivo.

Na educação, é por meio dos processos miméticos que as crianças adquirem tanto o comportamento em situações sociais na formação de hábitos que "inscrevem as normas sociais nos corpos das crianças e dos jovens", quanto o sentido temporal dos adultos. A mímesis se caracteriza inicialmente em imitar as ações de modo criativo e inventivo para dar respostas e modificar o significado das coisas. A aprendizagem se apresenta como o movimento pelo qual a criança assimila o

5 Essa questão é abordada por Benjamin na leitura de Edmund Bergler (1936) e de Ernst Simmel (1920), que analisaram o jogo da perspectiva da psicologia e da psicanalise. BENJAMIN, Passagens. Belo Horizonte: Ed. UFMG, 2009, (O 11 a, 1), p. 551-2. 
sentido do tempo linear e homogêneo: a "consolidação da economia temporal nos corpos das crianças e dos jovens estabelece uma ordem temporal generalizável e desprendida de conteúdos" adaptando-os aos interesses da sociedade.(GEBAUER e WULF, 2004, 57-8)

Em síntese, para Gebauer e Wulf, a capacidade mimética de voltar-se para o outro e para o mundo possibilita um conhecimento do outro e de si próprio que "não exige nenhuma alusão conceitual". A criança se reconhece como alguém que possui sensações e pensamentos próprios nos processos miméticos de adaptação ao outro. Assim também a "capacidade mimética pode perceber e processar o contraditório e diversas intensidades sem colocar estas em uma lógica bipolar". Nesse movimento de percepção, o "incompatível pode permanecer enquanto tal e ser apropriado mimeticamente" sem a necessidade de submeter tudo a uma ordem. (GEBAUER e Wulf, 2004, 88-89)

Essa breve explicitação dos conceitos de jogo e brincadeira a partir de alguns autores direta ou indiretamente referidos por Walter Benjamin visa a retomar seus escritos no aprofundamento do significado de capacidade mimética e da cognição infantil. O modo como a fantasia, a imaginação criadora enquanto o modo de aprendizagem perpassam a obra de Benjamin o colocam em confronto com determinadas leituras pedagógicas como a leitura iluminista e rousseauneana, bem como com a epistemologia de Piaget, tanto nos pressupostos de uma historia linear e homogênea que envolvem essas leituras e que Benjamin identifica como expressões da estrutura dominante burguesa, quanto na possibilidade de outros parâmetros de educação a partir da identificação da capacidade mimética da criança.

Por fim, pretende-se levantar algumas questões sobre a relação entre educação e política nos escritos de Benjamin. Embora os fragmentos aqui abordados possam parecer a rememoração de momentos felizes da infância do autor, não se trata de lamentar a felicidade perdida, mas sim aquilo que se perde no processo de educação formal. O que se pretende realmente sugerir é que a criança, esse "pequeno ditador" que a educação adapta ao mundo adulto, traz potencialidades que precisam ser analisadas para poderem florescer. A lembrança 
da infância não se apresenta como a busca de um tempo idealizado e perdido, mas a tentativa de identificar no presente os sinais para uma possível reflexão sobre os caminhos da educação. A relação da educação com a política se expressa na leitura e crítica dos limites do presente.

\section{Jogo e brincadeira infantil}

A imitação - assim se poderia formular - é familiar ao jogo e não ao brinquedo. (BENJAMIN, 2002, 93)

Cabe salientar que também o conceito infância apresenta um duplo significado no contexto dos escritos de Benjamin: em muitas situações, refere-se à origem da humanidade e da história, ao complexo processo de produção da memória, implicando as formas psicológicas de formação do consciente e do inconsciente, base para as observações de Benjamin sobre o mito. Por outro lado, em vários fragmentos escritos ao longo da vida Benjamin se refere à infância como o período de aprendizagem do mundo e de socialização da criança no processo de formação para a vida adulta. Ora, esses momentos interagem entre si e se articulam nas formas de expressão e de conhecimento de si no movimento de educação. Nosso objetivo não é explicitar a noção de infância, mas é selecionar alguns desses escritos para refletir sobre a questão do significado do jogo na educação infantil, que se concentra na ludicidade na brincadeira e na sua importância no processo cognitivo da criança. A atividade lúdica, na sua espontaneidade, é a principal forma de manifestação da criança nos primeiros anos de vida e se apresenta como uma forma indispensável de educação afetiva, sensorial e de conhecimento do mundo circundante.

Tendo como pressuposto que a ambiguidade que a noção de jogo encerra na medida em que é extensivo a diversas formas de ação, iniciamos por uma breve abordagem filológica. Em algumas línguas jogo, (Spiel, play, games, jeu, juego, gioco) diferencia-se do termo brincadeira: significa o modo de liberar energias físicas, psíquicas e espirituais de modo espontâneo, isto é, sem o compromisso inicial com normas e valores sociais. Para a criança, o jogo ou a brincadeira desenvolvem suas capacidades subjetivas, a sensibilidade, o raciocínio e a 
imaginação, apresentando-se como uma forma de conhecer o mundo e de conhecer-se a si mesma, de situar-se no contexto social, ou seja, uma aprendizagem de suas potencialidades físicas, imaginativas e intelectuais e do seu entorno.

Dessa perspectiva, as brincadeiras infantis assumem uma especificidade enquanto processo de cognição e de socialização da criança, pela externalização de capacidades individuais e possibilidades de comunicação e interação com os companheiros de brincadeira. Como a criança é imperativa (um pequeno ser que "dá ordens"), as brincadeiras são o modo ideal de socialização, de compartilhamento e de convivência com o outro, na aprendizagem do respeito à diferença. A criatividade se expressa na medida em que a fantasia e a imaginação servem para interagir com os outros e com a cultura. Embora as teorias do jogo acentuem que nunca se joga sozinho, mas sempre em interação com o outro, a inserção das novas tecnologias eletrônicas possibilitou o isolamento do jogador que, mesmo jogando com outros, se encontra isolado diante de um aparelho.

A atenção de Benjamin pela cognição infantil se volta a explicitar as características da mímesis enquanto movimento de aprendizagem de si e do mundo que tem como base a imaginação criativa. Ao brincar a criança imita e cria; por meio do brincar, desenvolve suas capacidades sensoriais e expressivas: o gesto, a dança, a encenação teatral, são muito importantes na formação da criança, na apropriação de linguagens que possibilitam interagir com o outro e realizar seu processo de socialização.

Os adultos, no processo de educação, não compreendem essa capacidade criativa da criança e, como acentua Karl Hobreker ${ }^{6}$, citado por Benjamin, a respeito da aridez dos livros infantis: a "criança exige dos adultos explicações claras e inteligíveis, mas não explicações infantis [...]. A criança aceita perfeitamente coisas sérias, mesmo as mais abstratas e pesadas, desde que sejam honestas e espontâneas".(BENJAMIN, 1985, 236-7)

$\overline{6}$ Karl Hobreker foi colecionador de livros infantis, cuja coleção apresentou em 1924 na obra Alte Vergessene Kinderbucher, publicada em Berlim pela Mauritius Verlag. BENJAMIN, W. Op. cit., 1985, p. 235.

Doutora em História pela UFPR, com estágio em Milão (IT). Pós-doutorado em Educação na UNICAMP. Professora de Filosofia Política e Estética na UFPR de 1976 a 2004. Professora do Programa de Mestrado e Doutorado em Educação da Universidade Tuiuti do Paraná. Brasileira, residente em Curitiba - PR. Email: anita.helena@libero.it 
A mímesis, além de imitação, se define como a capacidade de engendrar semelhanças. Para Benjamin, a brincadeira infantil se constitui na escola da capacidade mimética. "Os jogos infantis são impregnados de comportamentos miméticos que não se limitam de modo algum à imitação de pessoas". Ao brincar, a criança transforma-se não apenas em "comerciante ou professor, mas também em moinho de vento e trem". A questão importante, para Benjamin, seria saber "qual a utilidade para a criança desse adestramento da atitude mimética", ou seja, se este dom que, nas sociedades antigas, possibilitava um "ajustamento perfeito à ordem cósmica", que significado teria numa sociedade na qual essa faculdade não é percebida no seu significado original nem apresenta uma função especifica, visto que a criança precisa adaptar-se ao mundo do adulto e ao contexto do trabalho na ordem social e política burguesa.(BENJAMIN, 1985, 108-109)

A significação política dessa questão ainda não foi suficientemente acentuada: o que significa, na sociedade burguesa, educar a criança, entendendo-se a educação como formação para a vida? Na estrutura social e ideológica burguesa, educar significa integrar a criança ao mundo adulto, mundo em que imperam determinadas relações de poder que se expressam em relações de autoridade e de subordinação especificas que, por sua vez servem, entre outras coisas, para perpetuar relações de propriedade. A vantagem (para a criança) é que essa sociedade também é plena de contradições e ambiguidades que, se identificadas no seu movimento, abrem sendas de questionamento e de exercício da criatividade. É o que nos sugere Benjamin quando diz que o "mundo perceptivo da criança está marcado pelos traços da geração anterior e se confronta com eles"; é o que acontece com as brincadeiras, que não são meras fantasias, mas aprendizagem, assim como o brinquedo, que é, ao mesmo tempo, imitação e confronto com o adulto. (BENJAMIN, 1985, 250)

Nesse contexto, "elucubrar pedantemente sobre a fabricação de objetos material educativo, brinquedos ou livros - que fossem apropriados para crianças é tolice". As crianças criam seus brinquedos a partir dos resíduos que encontram no "lugar de trabalho onde visivelmente transcorre a atividade sobre as coisas". Com eles, "formam para si o mundo das coisas" (BENJAMIN, 1987, 18-19) e 
desenvolvem suas potencialidades imaginativas e racionais formando sua identidade. A brincadeira, muito mais que imitação do mundo adulto, é atividade criativa que descobre correspondências, que improvisa soluções e reinventa os significados.

A atitude mimética consiste em reconhecer semelhanças e correspondências (entre momentos do jogo e o mundo social, entre os gestos e os símbolos linguísticos, por exemplo); os jogos infantis se constituem de movimentos e ações que transcendem a mera imitação e permitem fazer relações e proceder a interações criativas atuando no processo de socialização da criança, que se apropria de comportamentos sociais pela mediação do jogo. Descobrir correspondências significa pressupor que os acontecimentos são semelhantes (porque produzidos no movimento da vida) e não idênticos (podem ser ressignificados) e, portanto, permitem estabelecer relações e dispor de novas maneiras os elementos sociais e culturais reconfigurando-os em novos contextos de leitura.

A criança tem o talento de ressignificar, de improvisar e de repovoar os espaços conforme sua imaginação e seus desejos; daí também ser a memória infantil o lugar em que se sobrepõe e interagem os tempos. Assim como a fantasia se intromete na realidade cotidiana da criança para criar novas significações das coisas, assim também o passado e o presente formam uma mesma trama, num tempo que é só presente.

Para o adulto, a vida se redefine pela vivência de um individualismo exacerbado e pela necessidade de estar permanentemente atento ao contexto da vida urbana. Os adultos vivem restritos às exigências do trabalho mecânico e instrumentalizado, que demarca o tempo linear e homogêneo do cotidiano e da história. Benjamin acentua o confronto entre estas duas realidades no processo de educação, confronto no qual as crianças são apresentadas à lógica formal e linear que orienta as relações sociais e ideológicas modernas que, aos poucos, transforma o seu mundo perceptivo. A "fada, por intermédio da qual alguém satisfaz um desejo, existe para todo mundo". Mas "são poucos os que sabem se lembrar do desejo formulado; por isso, só poucos são os que, mais tarde, na própria vida, reconhecem a satisfação proporcionada". (BENJAMIN, 1987, 252) 
A faculdade mimética se exercita no voltar-se para o mundo circundante e misturar-se com as coisas a fim de decifrar seu significado oculto. A cognição infantil ocorre na relação entre o jogo e a imersão nas coisas até identificar-se com elas no momento da brincadeira, sendo que "é justamente através desses ritmos que nos tornamos senhores de nos mesmos", 7 ou seja, constrói-se a nossa identidade. Ao brincar a criança busca semelhanças, as quais possuem uma particularidade: sua percepção ocorre "num relampejar. Ela perpassa, veloz e, embora talvez possa ser recuperada, não pode ser fixada" como acontece com outras percepções. Podemos dizer que a percepção das semelhanças transcende o sensível imediato e, se não for reconhecida na sua efemeridade e transitoriedade, em sua temporalidade própria, perde-se, dilui-se como sonho. (BENJAMIN,1987, 100-101)

A faculdade mimética enquanto percepção das semelhanças e das possíveis correspondências, própria da brincadeira, pode ser encontrada na linguagem oral ou escrita, podendo emergir no ato de leitura que, conforme as circunstâncias, pode entrecruzar e reunir significados, fazendo "o espirito participar daquele segmento temporal no qual as semelhanças irrompem do fluxo das coisas, transitoriamente, para desaparecerem em seguida". (BENJAMIN, 1985, 112)

A linguagem é um conceito central nos escritos de Benjamin, tema que ele aborda em vários ensaios e de formas diferenciadas. Articulada com a noção de mímesis, permite entender a formação da criança e o modo como ao conhecer-se, conhece o mundo. Linguagem e mímesis se entrelaçam nos significados explícitos e latentes que podem se evidenciar na expressão. Tem-se que ter em conta "o duplo sentido da palavra leitura, em sua significação profana e mágica": (BENJAMIN, 1985, 112)

\footnotetext{
7 Impressiona como Benjamin identifica a capacidade mimética da criança na sua imersão nas cores, mostrando que a criança se volta para o mundo e nele busca formar sua identidade por meio da atividade da imaginação. A criança se transporta "para dentro do quadro", entra na "nuvem de cores se diluindo", tinge-se "de acordo com a paisagem na janela", viaja dentro das bolhas de sabão e se mistura "ao jogo de cores de suas cúpulas "até que se rompam. O encantamento infantil com as cores é abordado em vários momentos da escrita do autor, desde um escrito de 1914-15, A visão das cores pela criança, até Infância em Berlim por volta de 1900, passando pelas imagens dialéticas de Rua de Mão Única e Imagens de Pensamento. In: BENJAMIN, W. Op. cit., 1987, p. 100-101.
}

Doutora em História pela UFPR, com estágio em Milão (IT). Pós-doutorado em Educação na UNICAMP. Professora de Filosofia Política e Estética na UFPR de 1976 a 2004. Professora do Programa de Mestrado e Doutorado em Educação da Universidade Tuiuti do Paraná. Brasileira, residente em Curitiba - PR. Email: anita.helena@libero.it 
O colegial lê o abecedário e o astrólogo, o futuro contido nas estrelas. No primeiro exemplo, o ato de ler não se desdobra em seus dois componentes. $O$ mesmo não ocorre no segundo caso, que torna manifestos os dois estratos da leitura: o astrólogo lê no céu a posição dos astros e lê ao mesmo tempo, nessa posição, o futuro ou o destino". (BENJAMIN, 1985, 112)

Esse duplo significado da leitura no contexto narrado implica a mudança estrutural da sociedade: para os antigos, o dom mimético estava presente na magia e na clarividência para identificar semelhanças extrassensíveis, situação que implicava uma concepção de mundo centrada no pertencimento do homem à tradição da comunidade e ao cosmos. Nas condições da sociedade moderna, esse dom "migrou gradativamente no decorrer dos milênios, para a linguagem e para a escrita". A linguagem se tornou o meio em que "as coisas se encontram e se relacionam", isto é, o meio de expressão da faculdade mimética enquanto percepção de semelhanças extrassensíveis. (BENJAMIN, 1985, 112)

Um dos inúmeros exemplos que encontramos nos escritos de Walter Benjamin sobre esse tema é o jogo de palavras muito conhecido na época Biedermeier, que consistia em tomar um conjunto de palavras sem aparente conexão entre si e organizar em um texto conciso e compreensível, sem alterar a ordem inicial das palavras. A atitude mimética se traduz em que, para as crianças, "palavras ainda são como cavernas, entre as quais conhecem curiosas linhas de comunicação". E Benjamin acentua que as "frases que no jogo uma criança forma com as palavras têm mais afinidade com as dos textos sagrados que com as da linguagem corrente dos adultos". O exemplo citado da organização das palavras "rosquinha, pena, pausa, queixa, futilidade" nos lembra mais a correspondência da formulação infantil com a expressão poética: o "tempo se lança através da natureza feito uma rosquinha. A pena colore a paisagem e se forma uma pausa que é preenchida pela chuva. Não se ouve nenhuma queixa, pois não há nenhuma futilidade". (BENJAMIN, 1987, 271-272)

O encanto das palavras se apresenta no que elas escondem, no não dito ou no indizível. Ao brincar com as palavras a criança se dispõe a receber a multiplicidade de sentidos que elas podem conter na sua reconfiguração. No texto, aprende a buscar o contexto, o invisível escondido, implícito, que desvela outras 
imagens e novos significados; dessa forma, reelabora elementos de cultura e de história que Ihe são dados no contexto social no qual se encontra inserida.

Se as palavras são cavernas que se interligam entre si para revelar seus mistérios, o conto de fadas se apresenta como uma das mais encantadoras expressões de comunicação mimética. Benjamin retoma os escritos de Hobrecker para dizer que a criança "constrói seu mundo com esses contos, ou pelo menos os utiliza para ligar seus elementos. O mesmo ocorre com a canção e com a fábula". Ao contrario de "uma certa sabedoria que tudo ignora sobre a infância algumas vezes supõe", as crianças não buscam nas fábulas a sua moral ou alguma lógica interna que as justifique. Elas apenas "se divertem muito mais com os animais que falam e agem como os homens que com os textos mais ricos em ideias", fazendo correspondências e exercitando a imaginação. (BENJAMIN, 1985, 238) Essa atividade, conforme Benjamin acentua retomando Baudelaire não é mera fantasia, porque a "imaginação é uma faculdade quase divina que percebe... as relações íntimas e secretas das coisas, as correspondences e as analogias".(BENJAMIN, 2009, J 31 a, 5) 330) Para o adulto, a linguagem literária e poética poderia possibilitar o reconhecimento de semelhanças extrassensíveis.

Enfim, a essência da brincadeira consiste na repetição; fonte dos maiores prazeres, a "obscura compulsão da repetição não é menos violenta nem menos astuta na brincadeira que no sexo". Tal compulsão se enraíza no princípio do prazer, que funda o desejo insaciável de "ir até o fim de todas as coisas, repetição e retorno, restauração de uma situação original, que foi seu ponto de partida". Trata-se tanto de vencer o medo do desconhecido ("experiências terríveis e primordiais") quanto de "saborear repetidamente, do modo mais intenso, as mesmas vitórias e triunfos". Repetir para dominar, conhecer e recriar. A repetição se encontra na base da formação de hábitos, que são "formas petrificadas, irreconhecíveis, de nossa primeira felicidade e de nosso primeiro terror". 8

8 BENJAMIN, W. Obras escolhidas - Magia e Técnica, Arte e Política. São Paulo: Brasiliense, 1985, p. 252-3. Os conceitos: princípio de prazer e princípio de realidade são próprios da teoria psicanalítica proposta por Freud, na explicitação do funcionamento psíquico. O jogo infantil tem como um dos objetivos realizar os desejos. Nesse movimento, faz-se progressivamente a aprendizagem da realidade, caminho para a satisfação procurada. Assim como a brincadeira infantil, também a arte teria a função de resolver as tensões entre esses dois princípios. Para

Doutora em História pela UFPR, com estágio em Milão (IT). Pós-doutorado em Educação na UNICAMP. Professora de Filosofia Política e Estética na UFPR de 1976 a 2004. Professora do Programa de Mestrado e Doutorado em Educação da Universidade Tuiuti do Paraná. Brasileira, residente em Curitiba - PR. Email: anita.helena@libero.it 
A repetição consolida o movimento de imersão no mundo, que caracteriza a capacidade mimética, com uma função formadora que consiste em interagir com o outro ou com as coisas de um modo intercambiável, ou seja, sem a rígida divisão em sujeito e objeto que caracteriza o conhecimento comum. Se a ideia de semelhança permite buscar novos sentidos, também possibilita mergulhar no mundo e identificarse com as coisas, visto que sujeito e objeto podem ser intercambiáveis na magia da brincadeira. Assim, esconder-se pode significar desaparecer (aos olhos do outro e de si): "bate-lhe o coração, ela segura a respiração. Aqui ela está encerrada no mundo da matéria"; misturar-se com o objeto que a esconde, diluir-se no espaço circundante: (...) a "criança que está atrás da cortina torna-se ela mesma algo ondulante e branco, um fantasma". Esconde-se sob a mesa e se transforma em "ídolo de madeira do templo onde as pernas entalhadas são as quatro colunas". (BENJAMIN, 1987, 39-40)

Viver intensamente o prazer e vencer o terror: ${ }^{9}$ a brincadeira infantil tem um duplo caráter implícito na atitude mimética. A ação infantil se realiza como movimento para o conhecimento e a criatividade, mas também como domínio dos mistérios e da natureza. Essa duplicidade aparece em vários momentos dos escritos: na brincadeira a criança se identifica com as coisas, transfigura-se no objeto atrás do qual se esconde e vive intensamente o risco dessa identificação. Atrás de "uma porta, ela própria é porta, está revestida dela como de pesada máscara e, como mago-sacerdote, enfeitiçará todos os que entram sem pressentir nada". Como se, no jogo, se vivesse permanentemente a empatia e o confronto com o mundo: a criança precisa ser encontrada, para se livrar do encantamento, tanto que, e se a descoberta demora, ela própria se revela "com um grito de

Marcuse, a forma estética é sensual e, na sua representação da sensualidade, a arte contesta o princípio de realidade e "invoca uma lógica tabu - a lógica da gratificação, contra a da repressão" (MARCUSE, Op. cit., 1972, p. 165). O tema da libertação do medo, que é abordado em várias imagens em torno das brincadeiras infantis, reaparece em Dialética do Esclarecimento, de Theodor Adorno e Max Horkheimer na reflexão sobre o mito contido na expectativa de progresso do pensamento e de dominação da natureza: a razão iluminista "tem perseguido sempre o objetivo de livrar os homens do medo e de investí-los na posição de senhores" (ADORNO T. e HORKHEIMER, M. Dialética do Esclarecimento. Rio de Janeiro: Zahar, 1985, p. 11).

9 Esta também é a expectativa da experiência amorosa do adulto, com a qual Benjamin faz analogia; os jogos com coisas inanimadas são o primeiro ensaio para "penetrar na existência e nos ritmos frequentemente hostis de um ser humano estranho" e, "justamente através desses ritmos que nos tornamos senhores de nós mesmos" ( BENJAMIN, op. cit., 1985, p. 252).

Doutora em História pela UFPR, com estágio em Milão (IT). Pós-doutorado em Educação na UNICAMP. Professora de Filosofia Política e Estética na UFPR de 1976 a 2004. Professora do Programa de Mestrado e Doutorado em Educação da Universidade Tuiuti do Paraná. Brasileira, residente em Curitiba - PR. Email: anita.helena@libero.it 
autolibertação". (BENJAMIN, 1987, 40) O que esta experiência tem de mágica e onírica, tem de mitológica, no sentido de que a mistura com a matéria pode anular as condições de formação da identidade ou gerar o oposto, enquanto domínio da natureza.

Nesse contexto, a lei da repetição aplica-se tanto ao movimento de aprendizagem infantil quanto ao cotidiano do adulto, com finalidades diferentes: se na brincadeira infantil serve para exercitar a fantasia e a invenção no movimento de conhecimento de si e do mundo, para o adulto pode significar consolidação de hábitos, reprodução de normas, adaptação ao instituído. Esse duplo caráter do jogo enfatiza tanto a sua importância na formação da identidade e na socialização da criança, quanto a sua função na consolidação de hábitos e no fortalecimento das formas de adaptação.

\section{A aprendizagem infantil na leitura de Benjamin}

Selos são cartões de visitas que os grandes Estados deixam no quarto das crianças. (BENJAMIN, 1987, 59)

Retomamos aqui alguns textos de Rua de Mão Única e de Infância em Berlim por volta de 1900, que servem para explicitar o significado da faculdade mimética da criança, enquanto uma relação ao mesmo tempo fraterna com as coisas e de confronto com o mundo adulto. A criança conhece o mundo por meio da brincadeira, fonte de formação de hábitos e apropriação de valores; ao mesmo tempo em que a criança explicita sua sensibilidade, seus afetos e desejos, interage com a cultura.

Iniciamos com um escrito intitulado Criança desordeira, para notar que a citada desordem se refere à ordem do mundo adulto. Ordem/desordem são aqui o confronto entre a atividade mimética que busca, imagina ou fantasia semelhanças por meio da brincadeira e a vida disciplinada, coerente e naturalizada do adulto e da sociedade. $O$ fragmento inicia acentuando a relação específica da criança com as coisas materiais, que ela separa em suas coleções: "cada pedra que ela encontra, cada flor colhida e cada borboleta capturada já é para ela o princípio de uma coleção". (BENJAMIN, 1987, 39 e 122-5) A prática de formar coleções tem como objetivo dispor de novas maneiras os objetos colhidos, formando novas 
constelações de significado. Assemelha-se ao trabalho do colecionador, abordado por Benjamin em um ensaio importante: Eduard Fuchs, der Sammler und der Historiker, (BENJAMIN, 1985b, 479) enquanto um modo de ressignificar tanto o objeto quanto a tradição. Por meio da brincadeira a criança transforma a ordem, rearranja as coisas e recupera a sua dimensão magica e lúdica. Por meio das coleções as "crianças decretam a renovação da existência por meio de uma prática centuplicada e jamais complicada". Assim como a "pintura de objetos, o recorte de figuras e ainda a decalcomania, as coleções fazem parte de "toda a gama de modos de apropriação infantil, desde o tocar até o dar nome as coisas", tudo faz parte do processo de renovação do mundo. (BENJAMIN, 1987, 229) Com seus guardados a criança não visa a "conservar o novo, mas sim a renovar o velho" de modo que ela, "neófita", possa se tornar seu dono. (BENJAMIN, 1987, 124)

Como o colecionador, que retira do contexto social o objeto a fim de buscar a sua significação original, a criança "caça os espíritos cujo rastro fareja nas coisas; entre espíritos e coisas ela gasta anos nos quais seu campo de visão permanece livre dos seres humanos". A busca por sentido nos jogos e brincadeiras, assim como nas coleções, são plenos de processos miméticos que se confrontam com a realidade do adulto. As semelhanças (materiais, auditivas, imagéticas, etc.) permitem relações não usuais entre imagens, palavras e sons, que requerem a imaginação: "seus anos de nômade são horas na floresta do sonho", que envolvem tudo o que ocorre na vida da criança. As gavetas do armário se tornam "casa de armas e zoológico, museu criminal e cripta". Qualquer proposta de "arrumação" aniquilaria esse mundo de sonho e fantasia. (BENJAMIN, 1987, 39 e 124) Assim como o colecionador, a criança retira do contexto habitual os objetos com os quais brinca e forma suas coleções e os devolve ao mundo com novas significações contribuindo, assim, para renovar o mundo.

Retomemos outra imagem rememorada da infância de Benjamin, A caixa de costura: entre as possibilidades de leitura, novamente a oposição ordem/desordem nos aparece, como a organização da vida cotidiana e familiar voltada para determinados objetivos de clareza e coerência, opostos ao lúdico e ao mágico do conto de fadas, ao caótico e irreverente do avesso do reticulado. Uma imagem que 
estabelece uma tensão entre a realidade e o invisível da fantasia e da rememoração. O que se apresenta à luz do dia esconde a escuridão do caos, do mistério, do que não se sabe ainda explicar com os instrumentos da razão. Esse "não sei quê" escondido e esquecido ou ainda reprimido, retorna em momentos imprevisíveis, do fundo da caixa de costura que, como a caixa de Pandora, esconde secretamente todos os mistérios do mundo.

\begin{abstract}
Já não conhecemos o fuso que feriu a Bela Adormecida e que a mergulhou num sono de cem anos. Porém, tal qual a mãe da Branca de Neve - a rainha - sentada à janela enquanto nevava nossa mãe também se sentava à janela com a caixa de costura, e não caíram as três gotas de sangue, pois ela usava dedal para trabalhar. Em compensação a cabeça do dedal era de um vermelho pálido, e ornavam-na pequenas escavações, vestígios de antigas agulhadas. Se o segurássemos contra a luz, cintilaria na ponta de sua cavidade escura, sobre a qual nosso dedo indicador estava tão bem informado. Pois gostávamos de nos apoderar daquela pequena coroa que, às escondidas, podia nos cingir. (BENJAMIN, 1987, 127-128)
\end{abstract}

A oposição acima citada não consiste no reconhecimento de valores, mas na possibilidade de a criança transitar limites e estabelecer relações de semelhança a partir de sua capacidade mimética que, no seu processo de aprendizagem e de socialização, descobre os significados tanto sociais quanto mágicos das situações que vivencia. Muitas vezes a criança não compreende o sentido e a utilidade dos objetos do cotidiano mas, pela evocação de semelhanças na forma da brincadeira, ela reconhece os elementos sociais e os sentidos consolidados e, ao mesmo tempo, cria novos significados por meio de sua imersão nas coisas. Desse modo, o dedal pode se transformar em coroa e, ao mesmo tempo, enfiado no dedo, dá a conhecer a função da costura. Para isso, a criança brinca com a ambiguidade das palavras "minha senhora" e "costureira" ressaltando a autoridade da mãe, rainha do lar.

A facilidade de transitar limites no processo de cognição infantil permite reconhecer os opostos e contraditórios que são apropriados ainda por meio da faculdade mimética, sem dissolver a tensão: enquanto a mãe faz alguns acertos na manga da camisa de marinheiro que o menino veste, o menino vive a oposição entre o sentir-se subjugado "com severidade máxima ao apetrechos de costura" que não guardavam "a menor relação com o sortimento multicor das sedas, das finas agulhas e das tesouras de diversos tamanhos". (BENJAMIN, 1987, 128) 
Outra questão que esta imagem dialética nos apresenta é a relação entre o esquecido e o presente, enquanto possibilidade de rememoração para abrir novos caminhos e possibilidades de realização. A "dúvida de se aquela caixa se destinava de fato à costura" retorna num passeio pela rua, na confusão entre a vitrine de uma confeitaria e a de um cabeleireiro: e se um daqueles carreteis falasse, como aquela "preocupação do pai de família", criação de Kafka e que "ninguém sabe o que é"? O que recordam os carreteis a respeito do impulso sexual? E as semelhanças se reproduzem trazendo à tona o esquecido (ou reprimido), agora em novo contexto, para despertar a releitura e a crítica do presente: "tantos anos me foram necessários para que, ao ver uma pequena gravura empalidecida, tivesse confirmada a suspeita de que toda aquela caixa fora destinada a outro tipo de tarefa que não à costura". (BENJAMIN, 1987, 128-9) Tarefas que se imaginam cruzando os limites entre o real e o sonho que nos move em busca de transformações, tendo em conta que "um acontecimento vivido é finito", demarcado pelo tempo, enquanto o "acontecimento lembrado é sem limites, porque é apenas uma chave para tudo o que veio antes e depois". (BENJAMIN, 1985, 37)

Seguir identificando semelhanças, evidenciar as tensões que permeiam 0 mundo social, reconhecer o que se esconde sob as aparências, essas são algumas das sugestões que emanam do texto desse filósofo-poeta. Um autor com a rara capacidade de vislumbrar no cotidiano o inusitado, o maravilhoso, o subversivo, como rememoração da infância ou como a vida da sociedade moderna. Cabe lembrar seu conselho a propósito da sua análise do Surrealismo: de "nada nos serve a tentativa patética ou fanática de apontar no enigmático o seu lado enigmático", mas se deve ir além; "só devassamos o mistério na medida em que o encontramos no cotidiano, graças a uma ótica dialética que vê o cotidiano como impenetrável e o impenetrável como cotidiano". (BENJAMIN, 1985, 33) Ou seja, o real não é o cotidiano imediato, pontual, mas o que ele esconde sob as aparências imediatas.

\section{A questão política permeando a educação}

Saber orientar-se numa cidade não significa muito. No entanto, perder-se numa cidade, como alguém se perde numa floresta, requer instrução. (BENJAMIN, 1985, 33) 
Ao evocar as imagens de sua infância Benjamin nos propõe questões fundamentais para refletir sobre s educação infantil. As práticas infantis não podem ser tratadas como meras brincadeiras, mas como um processo cognitivo que levanta uma questão da maior pertinência política: trata-se de mostrar que a educação não é neutra e a sua tarefa central deveria ser a superação de um conhecimento meramente informativo e utilitário, para transformar-se em um processo de releitura do passado a fim de permitir às novas gerações a transformação do presente. $O$ processo educativo entrelaça-se com a política e a história: não se pode prescindir do passado, mas a formação implica um confronto com ele, a fim de descobrir suas novas significações.

Se a faculdade mimética consiste em descobrir semelhanças e estabelecer correspondências e se a brincadeira é o modo privilegiado de exercer essa atividade a fim de desenvolver a cognição infantil, por que no processo de educação formal ess a capacidade não é incentivada? Isso se identifica nos escritos de Benjamin sobre a escola do início do século XX que, nas lembranças do autor, aparece como cansativa, enfadonha, aliviada apenas pelo mergulho nos livros ou pelas fugas à biblioteca.

No processo de formação esse mundo de magia e de fantasia, essa capacidade de conectar semelhanças e criar novos sentidos com imagens e palavras se perde no curso da educação formal. Como Benjamin nos diz em O jogo das Letras, "nunca podemos recuperar totalmente o que foi esquecido". E, quem sabe, seja melhor assim. "O choque do resgate do passado seria tão destrutivo que, no exato momento, forçosamente deixaríamos de compreender nossa saudade". Memória e esquecimento se articulam e se completam. Mas o esquecimento, às vezes, se consolida no adulto de tal maneira que este não consegue mais compreender a infância. O esquecido, no fundo, está presente na consolidação de hábitos, muitos deles formados no ritmo das brincadeiras infantis. E quando menos se espera retorna, por motivos simples como a presença de uma caixa de brinquedos; mas a lembrança se faz saudade, porque o adulto que se é no presente perdeu a confiança na magia e na fantasia. E este é um caminho sem volta: como diz Benjamin, "posso sonhar como no passado aprendi a andar. Mas isso de nada 
adianta. Hoje sei andar; porém, nunca mais poderei tornar a aprendê-lo". (BENJAMIN 1987, 104-5)

Isso não significa lamentar a felicidade perdida, mas admitir os limites de nosso conhecimento e a fragilidade das representações que formam o nosso modo de ser e consolidam o poder na sociedade moderna. A criança ainda não sabe dos valores burgueses, dos conceitos cristalizados que respondem às necessidades de estabilidade e segurança, do sentido preciso da censura nem das instâncias controladoras da moral convencional. Sua força e, ao mesmo tempo, sua fragilidade, se apresentam nas pulsões vitais ainda não domesticadas, na tendência ao lúdico, ao evanescente e ao impreciso misturar-se das cores, como nuvens nas quais mergulha para conhecer, mas prescindindo da coerência e da objetividade tão preciosas aos adultos.

A capacidade mimética própria das expressões infantis poderia se apresentar, num contexto educativo, como algo a ser preservado. $O$ conhecimento da mímesis no processo de educação ainda precisa ser aprofundado e se apresenta como uma possibilidade ainda a ser explicitada. Sendo a mímesis uma forma inovadora e criativa de a criança conhecer e interagir com os outros e com o mundo, pode ser também uma forma criativa de renovação social, caso se aprofunde suas possibilidades educativas, visto que a brincadeira permite a apropriação de elementos do mundo adulto de forma inovadora e capaz de contribuir para transformar relações e interpretações.

O aspecto político a ser enfrentado na educação se vincula tanto a preservar a "conexão entre a imaginação e o tecido de inervação física que foi rompido na cultura burguesa", quanto em recriar as condições de exercício da faculdade mimética na educação infantil, o que exigiria mudança estrutural de métodos e currículos. O que acontece, em geral, no processo de educação escolar, é o sufocamento do lúdico, da fantasia e da imaginação com um contínuo trabalho de naturalização dos conceitos em nome de valores a serem preservados.

Outra questão a ser abordada em profundidade seria a da aplicação das novas tecnologias no processo de educação. Se não se alterarem as abordagens pedagógicas e se não forem superados os mitos que envolvem processo educativo 
escolar de nada adiantarão estes mecanismos de aprendizagem, cujo potencial de conhecimento ficará subordinado aos limites de visões enrijecidas e cristalizadas da vida e da história.

Para Rochlitz, a questão política e histórica se encontra em "salvar certas significações ocultas, suscetíveis de revelar o presente a ele mesmo e de guiar uma ação decisiva colocando fim a toda opressão". Essa tarefa, que seria do historiador, Benjamin a toma para si esforçando-se "por salvar uma significação ameaçada e que forma uma constelação precisa com uma experiência crítica do presente". (ROCHLITZ, 2003, 319-320) Ora, o processo educativo enquanto formação humana assume dessa fonte o seu significado político.

Para concluir, esse tema exigiria aprofundar outros conceitos benjaminianos como a crítica à modernidade, o conceito linear de história, bem como o mito do progresso e da racionalidade a partir das noções de sonho e de despertar. Enfim, "integrar o novo mundo ao espaço simbólico. A criança é capaz de fazer algo que o adulto não consegue: rememorar o novo", (BENJAMIN, 2009, K1a, 3, 435) o que significa implementar um método de educação inovador, com uma nova abordagem política.

Doutora em História pela UFPR, com estágio em Milão (IT). Pós-doutorado em Educação na UNICAMP. Professora de Filosofia Política e Estética na UFPR de 1976 a 2004. Professora do Programa de Mestrado e Doutorado em Educação da Universidade Tuiuti do Paraná. Brasileira, residente em Curitiba - PR. Email: anita.helena@libero.it 


\section{REFERÊNCIAS}

ADORNO T. e HORKHEIMER, M. Dialética do Esclarecimento. Rio de Janeiro: Zahar, 1985.

ARENDT, H. II pescatore di perle: Walter Benjamin (1892-1940). Milano: Mondadore, 1993.

BAUDELAIRE, C. O pintor da vida moderna. In: Obras estéticas. Filosofia da imaginação criadora. Petrópolis: Vozes, 1993.

BAUDELAIRE, C. O spleen de Paris. Pequenos poemas em prosa. Rio de Janeiro: Imago, 1995.

BENJAMIN, W. Obras escolhidas - Magia e Técnica, Arte e Política. São Paulo: Brasiliense, 1985.

BENJAMIN, W. Obras escolhidas II - Rua de Mão Única. São Paulo: Brasiliense, 1987.

BENJAMIN, W. Passagens. Belo Horizonte: Ed. UFMG, 2009.

BENJAMIN, W. Reflexões sobre a criança, o brinquedo, a educação. São Paulo: Duas Cidades e Ed. 34, 2002.

BENJAMIN, W. Gesammelte Schriften II, 1, 2 und 3 (Aufsaetze, Essays, Vortraege.) Frankfurt a.M., Suhrkamp Verlag, 1985b.

BENJAMIN, W. Gesammelte Schriften V, 1 und 2 (Das Passagen-Werk). Frankfurt a.M. : Suhrkamp Verlag, 1991.

BUCK-MOORS, S. Dialética do olhar. Belo Horizonte/Chapecó: Ed. UFMG/Argos, 2002.

DUARTE, R. e FIGUEIREDO, V. (Orgs.) Mímesis e Expressão. Belo Horizonte: Ed UFMG, 2001.

GEBAUER, G. e WULF, C. Mimese na cultura. São Paulo: Annablume, 2004.

GRAMSCI, A. Maquiavel, a política e o Estado moderno. Rio de Janeiro: Civilização Brasileira, 1978.

HUIZINGA, J. Homo ludens. O jogo como elemento da cultura. São Paulo: Perspectiva, 1973.

MARCUSE, H. Eros e civilização. Uma interpretação filosófica do pensamento de Freud. Rio de Janeiro: Zahar, 1972. 
McCOLE, J. Walter Benjamin and the antinomies of tradition. London: Cornell University Press, 1993.

ROCHLITZ, R. O desencantamento da arte: a filosofia de Walter Benjamin. São Paulo: Edusc, 2003.

SCHILLER, F. A Educação Estética do Homem. São Paulo: lluminuras, 1989.

SCHLESENER, A. H. Os tempos da História. Leituras de Walter Benjamin.

Brasília: Liber Livro, 2011.

WOLIN, R. Walter Benjamin an Aesthetic of Redemption. University of California Press, 1994. 